\title{
Concept of Developing Communicative Environment in the Problem Field of Giftedness
}

\author{
Marina Ivleva \\ Faculty of Humanities and Social Sciences \\ Department of Social Philosophy \\ Peoples' Friendship University of Russia (RUDN University) \\ 6 Miklukho-Maklaya Street, Moscow, 117198, Russia \\ E-mail: marinanonna@yandex.ru
}

\begin{abstract}
The article aims to clarify a number of the most significant provisions, studies of giftedness in its connection with the problems of the environment. This is an analysis of the role of the environment in terms of its impact on gifted children, and the study of various approaches to the development of strategies and specific techniques for the development of giftedness. The author substantiates the proposition that one of the most promising areas for the development of a methodical apparatus for working with gifted children is the direction associated with the creation of a developing environment, more specifically, the development of communicative environment (DCE).
\end{abstract}

Keywords-Giftedness; programs for the development of gifted children; development of communicative environment (DCE); creation of DCE; properties of DCE; DCE functions

\section{INTRODUCTION}

Our analysis of theoretical, experimental and practical developments in the field of psychology of giftedness [1] indicates that the universally recognized the factor of the environment in the development. The article attempts to clarify the theoretical positions that are the most significant for the purposes of the study of giftedness in its connection with the problems of the environment.

The category of the environment has entered the scientific use through the discussion of the correlation of biological and social in human nature. An abstract philosophical examination of this problem led to the formulation of the position of the maxima in the evaluation of this ratio. At the extreme poles, the Marxist-Leninist tradition has settled down with the absolutization of the role of society and the biologizational approach that regards man as a unique biotechnical machine. Modern ideas allowed to draw a conclusion about the biosocial nature of man and led to an understanding of his systemic integrity. Human development is not realized as a result of the mechanical connection of two lines, but through their dialectically

This paper was financially supported by the Ministry of Education and Science of the Russian Federation on the program to improve the competitiveness of Peoples' Friendship University (RUDN University) among the world's leading research and education centers in the 2016-2020 (The Agreement number 02.A03.21.0008). inextricable interconnection.

\section{FROM THE HISTORY OF ENVIRONMENTAL APPROACH}

As a result of an active study of the environment in the 1970 s, at this moment it can be argued that a new direction the psychology of the environment - has emerged and was formed. In its "baggage" lies a significant potential for knowledge, the development of an extensive methodological and theoretical basis, formed theoretical positions on a number of key aspects, a variety of perspectives of the problem and directions in its study. Among them are the problems of the correlation of biological and social; Nature of the environment; Its interaction with the human; Interference of the subject and environment; The effect of the environment on a person; Features of perception of the environment; Human reaction to interaction with the environment; Environment ecology; Conditions and mechanisms of adaptation to the environment [2].

Analysis of the conceptual apparatus of the category "environment" made it possible to distinguish the following conceptual components in its definitions: the space-temporal body of human being, the whole world, the means of selfdetermination of a person, the space of human behavior, the sphere derived from social processes, the means of human self-expression, the set of stimuli surrounding the person Social, material and spiritual conditions of its existence.

The interaction of the child with the environment is due to two opposing tendencies, namely, changes in the external environment under the influence of human activity and changes in the person himself under the influence of the environment, which is reflected in the features of the psyche. The mechanism of interaction between a person and the environment can be represented in the following way: as a result of the interaction of the individual with the surrounding conditions, a special intermediate reality is formed in an image in which various components of the social environment are presented (ideological, economic, technical, cognitive, sociocultural and motivational) [3]. Under the influence of this image, the child develops. That is, the type of child's development is formed in accordance with the way of life that the environment provides: the socioeconomic conditions of the family, the level and 
characteristics of the socio-cultural development of the life environment that provide opportunities for development. However, the path of personal development of each person is strictly individual and depends on many factors.

\section{THE ROLE OF THE ENVIRONMENT IN THE PROCESS OF SOCIALIZATION OF GIFTED CHILDREN}

The question of the role of the environment in the process of socialization is one of the key issues in modern psychology of giftedness. The following fact are important: according to the published data, the problem of socialization is one of the most difficult problems for gifted children; according to Rowlands [4], most gifted children have a negative self-concept. That is why in a number of programs an emphasis is placed on the social environment with increased attention to the family environment (for example, the works of Heller, Perlet [5]).

Recognizing that the macro environment (public, "broad" environment) has a serious impact on the development of gifted children, experts are nonetheless sure that it is the family as a component of the microenvironment that ensures the concretization of this influence, acts as the condition that organizes the assimilation of the norms and requirements of society, communicates the tasks put forward by the social milieu to the child, and realizes them. So, according to Elkonin [6], from an externally homogeneous environment, each individual actively chooses one and rejects its other elements, as a result of which an individual, personal environment is formed for each individual within the general environment.

Assessing the role of the environment in terms of its impact on gifted children, it should be recognized that it contributes to the process of their mental (cognitive and personal) development. That is why the term "developing environment" is quite appropriate and on the whole adequately reflects the essence of social interaction processes and the direction that it gives to child's development. It is important to note that during this development, it is understood, according to the point of view of Russian psychology, a complex involutive evolutionary progressive movement takes place, in the course of which progressive and regressive intellectual, personal, behavioral, activityrelated changes occur in the person himself (Vygotsky [7], Leont'ev [8], Ananiev [9], etc.). The general characteristics of development, according to Antsyferova [10], are: irreversibility, progress / regression, unevenness, preservation of the previous in the new, unity of change and preservation. In this connection, it should be emphasized that social interaction, as Poddiakov points out [11], can be presented not only as supporting and helping, but also as an opposing, inhibiting and slowing to the process of learning and development.

Taking into account the factor of the developing environment allows solving many problems of gifted children, since it is the developing environment that promotes the development of a positive self-concept, the concept of creative conformism for resolving the conflict between maintaining independence and subordinating group interests, reducing the influence of negative social stereotypes, suppressing the actions that give rise to negative reaction of others, the removal of the blockage of the creative energy of a gifted child, the formulation of adequate ideas about oneself, the world, the search for one's own place in society, the stimulation of positive mental development and even the discovery of the giftedness by the gifted child himself.

\section{CONCEPTUAL PROVISIONS FOR Elaborating THE STRATEGIES AND TECHNIQUES FOR THE DEVELOPMENT OF GIFTEDNESS}

Evaluating different approaches to elaborating the strategies and specific methods for the development of giftedness, one can not ignore the most general provisions of the concept of the environment. In particular, two interrelated types of social interaction, which differently change the direction of the process of cognitive and personal development of a gifted child, the laws of this process, its structure and results, are help and opposition. The ratio of these two fundamental types of relationship between the child and the environment is the essence of the development process. Accordingly, they should be comprehended and translated into programs for gifted children from the position of searching for their constructive opportunities in terms of development. However, we should not forget that these programs should not be based on the absolutization of the social principle in a gifted child, or be based on a particular aspect of development. It is necessary to take into account all the features of the integral biosocial nature of a person and the mutual influence of these levels on each other. To this end, programs for gifted children should be based on the achievements of the natural sciences in addressing the question of the correlation of biological and social in human nature, the results of integrative biology and humanitarian research. This knowledge of the laws of age psychophysiology and the nature of individuality, takes into account the sexual characteristics of the course of higher mental functions. The introduction of this approach into the practice of teaching and educating gifted children will help overcome the tendency to average views on the personality of a gifted child, create conditions for the adequate deployment of the brain development programs laid down in the gifted child and the formation of an environment suitable for realizing his individual capabilities.

The training methodology, in turn, should be based not on the typical methods, but on specific methods and means of teaching and upbringing, coming from the requests and real capabilities of the gifted child, but not on the notions of adults about what is needed. In determining the quantitative composition of the group of trainees, the spatial organization of the environment, the formation of emotional and motivationally-demanding spheres, etc. One must take into account the nature of the individuality and its biogenetic foundations in order to form a reliable foundation for developing practical recommendations for the creators of programs for gifted children to timely identify "painful" 
points, the problems of gifted children, to overcome and prevent any objectionable development.

There are various strategies for building relationships with the environment. The most common are two: adaptation to the environment and the organization of the environment, its reproduction. The first strategy envisages that the burden of adjustment completely lies on the gifted child, it is not shared by its microenvironment. The second strategy is based on the activity of a gifted child aimed at creating, building a system of new relations, corresponding spheres of his life activity and identifying conditions, ways, opportunities for further development. That is, the active role of a gifted child is strengthened by entering into a number of new groups of people actively influencing the general development situation. The variety of the amateur performances by gifted children is expanding at different levels, in different forms and types of presented.

Based on an understanding of the developing orientation of the environment, not just to promote the development of another, but also the self-development (that is, the environment becomes the developing environment if it promotes the mutual development of the people included in it as subjects of this process), we emphasize the term "selfdevelopment". Thus, the active role of the growing gifted child is emphasized as at first a spontaneous, and then a conscious subject of his life. The second driving force behind the development of the personality of a gifted child are adults, who act not simply as a condition for personal development, but participants in this process, its subjects, which stimulate or suppress the child's own activity. Conjoint activities and active communication of adults and children in real contacts with each other are the signs of an environment in which the personality of the gifted child and adult develops.

The child's attitude to the environment is an important aspect of his development. Ensuring the optimal psychological and personal development of a gifted child is possible through the creation of the DCE, the change in the content of activities of all its subjects, that is, people entering into interaction with gifted children: teachers, parents, other children, family doctors or pediatricians, librarians, social workers.

\section{CREATION OF THE DEVELOPING COMMUNICATIVE ENVIRONMENT AS AN INNOVATIVE PROCESS}

The thesis defended by us and the concept based on it is based on the assertion that the most promising direction in the development of the methodological apparatus for working with gifted children is the direction associated with the creation of a developing environment, more specifically, the developing communicative environment (DCE) [12]. This concept is based on the following provisions: the giftedness as a manifestation of the creative nature of the psyche (Matyushkin [13]); the existence of different levels of actualization of giftedness; the conditionality of the level of actualization of giftedness by the presence of appropriate natural and social conditions that ensure its manifestation in the form of natural inclinations, inclinations and abilities, the role of communication in the process of socialization (KanKalik [14]). On these provisions, a practical setting is based on creating conditions for the manifestation of giftedness as the emerging systemic quality of the psyche (Panov [15]).

The creation of the CSW is an innovative process, as evidenced by the analysis of the experience of developing and implementing programs for gifted children in Russia and abroad. We believe that the establishment of the DCE is a necessary condition for the full-fledged intellectual and personal development of a gifted child, since, on the one hand, it allows solving the most typical and clearly expressed problems of gifted children, primarily socio-adaptive (communicative incompetence, the difficulty of the process of socialization and social adaptation, Inadequate selfconcept and self-esteem, negative attitudes towards oneself, lack of social skills and abilities, inability to solve problems, etc.). On the other hand, its creation contributes to the maximum development and expression embodied in a gifted child of uniqueness, uniqueness, individuality. The realization of this individuality is creativity, the level of development and manifestation of which depends on personal qualities and environmental characteristics.

The term developing communicative environment (DCE), used by us, adequately reflects the essence of social interaction processes and the direction that it gives to the development of gifted children. The DCE is understood as a system of key factors that have a decisive impact and are favorable for the development of the child through optimal communication with him. Its structural components are people (including a gifted child), culture, the natural and material world around the child. Each component has a different degree of activity. If you try to graphically represent the DCE, then it can take the form of an ellipse with two equivalent foci (child and adult). All the rest of the space is filled with such components of the RKS as culture and nature, and the background, the thread, connecting all the above elements, will be communication.

DCE can be considered in three interrelated planes: 1) as a system; 2) as a process; 3) as an individual or cumulative result of this process. The work of the DCE is characterized in accordance with the principles of systemic. It appears as a whole, not reducible to the sum of the properties of its constituent elements (gifted child, educator, culture, nature) and not derived from the properties of the whole, by the system. Each element, property and attitude of the DCE depend on their place and functions within the whole.

Another of its properties is the structure, or the presence of a network of connections and relationships, which, as part of the structure, can determine the behavior of the DCE. DCE has another property - hierarchy, that is, each of its components in turn can be considered as a system. Another property - the interdependence of DCE from the environment in a broader sense (habitat), in the process of interaction with which the DCE exhibits its properties, being at the same time an active component.

Finally, the DCE is characterized by a multidimensional representation due to its complexity. As a result, adequate 
knowledge of the RCC requires the construction of many different models, each of which describes only a certain aspect. It is established that all the pedagogical and psychological influences of the environment aimed at a gifted child represent a single psychological space for the existence and development of the child.

A gifted child is seen as an active subject of all relationships that form in the educational environment, and the personality of the student is the central component of this environment. The study and assessment of environmental factors is conducted taking into account their relationship to the subject's qualities of the student.

Realization of developing potential of the educational environment is carried out by conjoint efforts of psychologists and teachers. Based on this, not only key areas of the psychologist's work with educators, but also their methodological support were identified. The scope of consideration included, among other things, the problems of helping teachers in their contacts with parents of gifted children, as well as assessing the effectiveness of the educational environment.

If we consider the concept of DCE as a generic one, its adequate description presupposes the construction of many different models, each of which reflects only a certain aspect of it. The main structural elements of the developing environment are a gifted child, an educator, culture, nature. While we don't want to belittle the importance of other subsystems in the DCE structure, we nevertheless consider training as the main condition and means for the mental and personal development of a gifted child. Accordingly, the central figures of the model of the developing environment are: a) gifted children - students and b) educators - teachers as the main subjects of the educational process.

The main directions of the work of a psychologist are work with educators of gifted children and gifted children themselves. If we summarize all the functions performed by the psychologist, not by the types of his activity, but by the content of his work, then such a list can turn out: educational-philosophical (expansion of knowledge), educational-mobilizing (humanization of subjects of the educational process), life-practical (to use the recommendations of psychologists in life), vocational (providing professional growth) and developing (purposeful overall development).

Consider, for example, the educational-mobilizing function, which is associated with the development in children and adults of the cultural, humanitarian position and the corresponding way of thinking and view of the world [16]. The main characteristics of this position are: subjective, author's attitude, expressed in the absence of claims for absolute truth; Value attitude, implying not detached contemplation, but a lively, active participation in any situation; The ability to use all the variety of communication tools that exist in culture.

\section{CONCLUSION}

From what has been said it follows that the most important component of the work of a psychologist in working with gifted children is the creation of a practical psychology of the pedagogue of a gifted child. Within the framework of this work, it will be possible to work together with a psychologist to design a DCE for each child. The work on creating a developing DCE for gifted children should become one of the important and relevant areas of the psychologist's work.

The expediency of carrying out this work is determined by: an urgent need to compensate for our lag in this area; the need to overcome the anti-intellectualist attitudes prevalent in society; the desire to ensure the full development of a gifted child and to achieve the optimal correspondence of specific programs to the characteristics of this group of children [17].

The content of this work is determined by the solution of the following tasks: to develop and test a system of measures aimed at improving the social environment of gifted children (climate in the family, school, learning conditions, relations with peers, etc.); To develop the creative mental parameters of the intellect of children along with its rational level; Increase the competence of the child in any field of activity [18]; Ensure the optimization of the process of socialization of children and overcome possible difficulties in their social adaptation; Promote the development of an adequate selfconcept and self-esteem, a fruitful attitude towards learning, to oneself and one's environment; To form and develop social skills and the ability to understand other people and be sensitive to them; Help to master the skills and skills in solving problems arising in the child.

Like any creative process, working with gifted children from the point of view of creating a PCS for them presupposes further searches and discoveries. Only the basic principle of working with gifted children remains unchanged: to bear responsibility for their future. Our own experience allows us to hope that work in this direction creates new opportunities both in studying the phenomenon of giftedness and in developing new programs for the development of gifted children [19].

\section{REFERENCES}

[1] Ivleva M. L. The Philosophical bases of psychological conception of giftedness. Textbook. M., 2011.

[2] Ivleva M.L., Bagramiants N.L., Ivlev V.Y., Oseledchik M.B. Methodological Principles of the Study of the Philosophical Foundations of Psychological Conceptions of Giftedness // Proceedings of the 2016 3rd International Conference on Education, Language, Art and Inter-cultural Communication (ICELAIC 2016). Advances in Social Science, Education and Humanities Research. Paris: Atlantis Press, 2017. Volume 40. P.48-52.

[3] Chistyakova O. Rationalization of Contemporary Culture and Education in the Context of Religious Resistance to Violence // Proceedings of the 2016 International Conference on Arts, Design and Contemporary Education. (ICADCE 2016). Advances in Social Science, Education and Humanities Research. Paris: Atlantis Press, 2016, v. 64, pp. 1192-1198.

[4] Rowlands P. Gifted children \& their problems. L.: J. M.Dent, 1974. 
[5] Heller K. A., Perlet K., Sierwald V. Longitudinal study of giftedness// Questions of psychology. 1991. No. 2. P. 120-127.

[6] Elkonin D. B. Child psychology. M., 1960.

[7] Vygotsky L. S. Problems of theory and history of psychology // SOBR. CIT. in 6 vols. vol. 1. M., 1982.

[8] Leontiev A. N. Activity. Consciousness. Personality: Textbook. Textbook forstudents / ed. Leontiev. - M : Meaning : Academia, 2004. - $345 \mathrm{p}$.

[9] Ananev B. G. Formation of giftedness // the Inclination and ability. L., 1962.

[10] Antsyferova L. I. The Psychological mediation of socialinter actions on personality, its development and the formation // Psychological study of social development of the individual. M., 1991.

[11] Poddjakov A. N. Problems in he study of exploratory behavior: a research about the behavior of children and not only children. M: RPsS. 1998.

[12] Bagramyants M. L. Psychology of giftedness: theory, experiment, practice: textbook. M., 2003.

[13] Matyushkin A. M. The Concept of creative giftedness // Questions of psychology, 1989, vol. 6. P. 29-34.

[14] Kan-Kalik V. A. To the Teacher about the pedagogical communication: The Book for teachers. M.: Education, 1987.

[15] Panov V. I. Giftedness and gifted children: ecopsychological approach. M., 2005.

[16] Chistyakova O. V. Human in a Mediatizing Postmodern World: Anthropological Meanings and Social Implications // Human. Society. Inclusion. № 2-1 (26), 2016. Published by Moscow State University of Humanities and Economics. P. 90-98.

[17] Bagramyants N. L., Ivleva M. L. Problems and prospects of modern professional education as a dynamic system // Proceedings of Moscow state technical University MAMI. 2012. Vol. 1. No. 1. P. 340-345.

[18] Chistyakova O.V. Russian Religious Philosophy as the Basis for State Identity // Journal of Eurasian Research. 2003. Volume 2. № 1. ISSN 1538-0378. P. 13-17.

[19] Ivleva M. L. The psychological concepts of giftedness: a theoretical and historical study. M., 2008. 